\title{
Insulin Administration for People with Type 1 diabetes
}

Boiroux, Dimitri; Finan, Daniel Aaron; Poulsen, Niels Kjølstad; Madsen, Henrik; Jørgensen, John Bagterp

Published in:

21st European Symposium on Computer-Aided Process Engineering

Link to article, DOI:

10.1016/B978-0-444-54298-4.50090-8

Publication date:

2011

Link back to DTU Orbit

Citation (APA):

Boiroux, D., Finan, D. A., Poulsen, N. K., Madsen, H., \& Jørgensen, J. B. (2011). Insulin Administration for People with Type 1 diabetes. In 21st European Symposium on Computer-Aided Process Engineering Elsevier. Computer Aided Chemical Engineering No. 29 https://doi.org/10.1016/B978-0-444-54298-4.50090-8

\section{General rights}

Copyright and moral rights for the publications made accessible in the public portal are retained by the authors and/or other copyright owners and it is a condition of accessing publications that users recognise and abide by the legal requirements associated with these rights.

- Users may download and print one copy of any publication from the public portal for the purpose of private study or research.

- You may not further distribute the material or use it for any profit-making activity or commercial gain

- You may freely distribute the URL identifying the publication in the public portal

If you believe that this document breaches copyright please contact us providing details, and we will remove access to the work immediately and investigate your claim 
21st European Symposium on Computer Aided Process Engineering - ESCAPE 21

E.N. Pistikopoulos, M.C. Georgiadis and A.C. Kokossis (Editors)

(C) 2011 Elsevier B.V. All rights reserved.

\title{
Insulin Administration for People with Type 1 diabetes
}

\author{
Dimitri Boiroux, Daniel Aaron Finan, Niels Kjølstad Poulsen, Henrik Madsen \\ and John Bagterp Jørgensen \\ ${ }^{a}$ Department of Informatics and Mathematical Modeling, Technical University of \\ Denmark, DK - 2800 Kgs. Lyngby(e-mail: \{dibo,dafi,nkp,hm,jbj\}@imm.dtu.dk)
}

\begin{abstract}
In this paper, we apply model predictive control (MPC) for control of blood glucose in people with type 1 diabetes. The two first control strategies are based on nonlinear model predictive control (NMPC). The first control strategy is based on meal announcement in advance, while the second one considers meal announcement at mealtimes only. They give a quantitative upper bound on the achievable control performance. The third control strategy is a feedforward-feedback control strategy. This strategy uses a time-varying setpoint to reduce the risk of hypoglycemia. The feedback controller computes the optimal basal insulin infusion rate. The feedforward controller consists of a bolus calculator. It computes the optimal bolus, along with the timevarying glucose setpoint. We test these three strategies on a virtual patient with type 1 diabetes. The numerical results demonstrate the robustness of the last control strategy with respect to changes in the model parameters and incorrect meal announcement.
\end{abstract}

Keywords: Type 1 diabetes, Nonlinear model predictive control, feedforward-feedback control

\section{Introduction}

The World Health Organization (WHO) estimates that more than 220 million people worldwide have diabetes. This number is likely to double by 2030 . In the USA, the budget for diabetes represents $10 \%$ of the health care budget, i.e. more than 130 billion dollars (132 billion dollars in 2002).

In people without diabetes, the blood glucose is controlled tightly around $90 \mathrm{mg} / \mathrm{dL}$ (5 $\mathrm{mmol} / \mathrm{L})$. Type 1 diabetes is a chronic disease characterized by an insufficient (effectively nonexistent) endogenous production of insulin, which leads to poor regulation of glucose concentrations in the blood. In particular, the deficiency of insulin causes sustained high glucose levels (hyperglycemia) that result in serious long-term health problems like eye, nerve, and kidney disease. On the other hand, too much insulin can result in very low glucose levels (hypoglycemia) which can pose immediate health risks. Consequently, exogenous insulin must be injected to regulate the blood glucose concentration as tightly as possible.

Usually, insulin treatment consists of the administration of rapid acting insulin through boluses (i.e., discrete insulin administration) at the time of meals. The size of the bolus is based on a measurement of the current blood glucose at mealtime and the (estimated) size of the meal. However, having measurements only at mealtime does not provide enough information about blood glucose. Consequently, people with diabetes often tolerate hyperglycemia in order to avoid hypoglycemia and its immediate effects. 


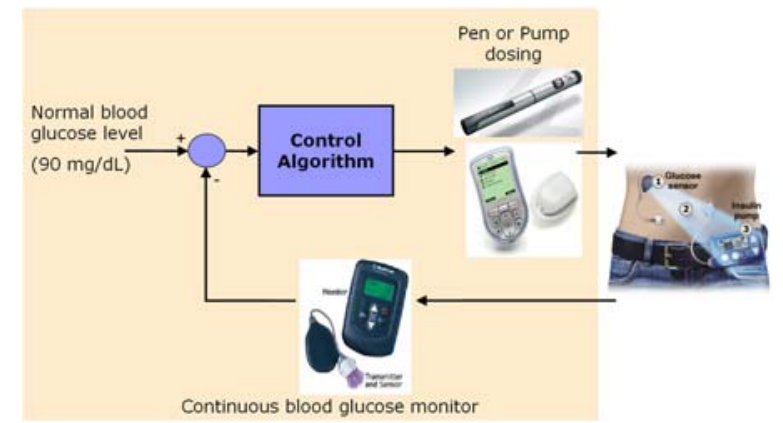

Fig. 1. Closed-loop glucose control. Glucose is measured subcutaneously using a continuous glucose monitor (CGM). Insulin is dosed either continuously by an insulin pump or discretely using an insulin pen

Continuous glucose monitors (CGM) can help to provide a better control of blood glucose. They measure the glucose concentration in the subcutaneous depot. Insulin pumps that continuously inject fast acting insulin have also been developed. Combining a CGM with an insulin pump can enable automatic insulin administration for people with type 1 diabetes. Such a medical device is called an artificial pancreas, and its principle is illustrated in Fig. 1. Several research groups work on aspects of control algorithms integrating the CGM and the insulin pump to automatically adjust insulin administration for people with type 1 diabetes, such as Cobelli et al. (2009) and Klonoff et al. (2009).

In this paper we use the model developed by Hovorka et al. (2004) and described in Boiroux et al. (2010b) to simulate a patient with type 1 diabetes. In the Hovorka model, the quality of the glucose control is limited by the time lag associated with subcutaneous-to-intravenous insulin absorption. This system property fundamentally limits the control quality that can be achieved in closed-loop insulin administration, as demonstrated in Boiroux et al. (2010a).

\section{Nonlinear Model Predictive Control}

In this section, we state the continuous-time optimal control problem and apply it to the computation of the optimal insulin profiles for people with type 1 diabetes. The optimal insulin administration is formulated as a bound constrained continuous-time Bolza problem

$$
\begin{aligned}
\min _{[x(t), u(t)]_{t_{0}}^{t_{f}}} & \phi=\int_{t_{0}}^{t_{f}} g(x(t), u(t)) d t+h\left(x\left(t_{f}\right)\right) \\
\text { s.t. } & x\left(t_{0}\right)=x_{0} \\
& \dot{x}(t)=f(x(t), u(t), d(t)) \\
& u_{\min } \leq u(t) \leq u_{\max }
\end{aligned}
$$

in which $x(t) \in \mathrm{R}^{n_{x}}$ is the state vector, $u(t) \in \mathrm{R}^{n_{u}}$ is the vector of manipulated inputs (insulin injection), and $d(t) \in \mathrm{R}^{n_{d}}$ is the vector of known disturbances (meals). We assume the state vector $\mathrm{x}(\mathrm{t})$ and the input vector $\mathrm{u}(\mathrm{t})$ to be constant between the sampling times and a constant sampling time $T_{s}=5 \mathrm{~min}$. Thus, we can use the multiple- 

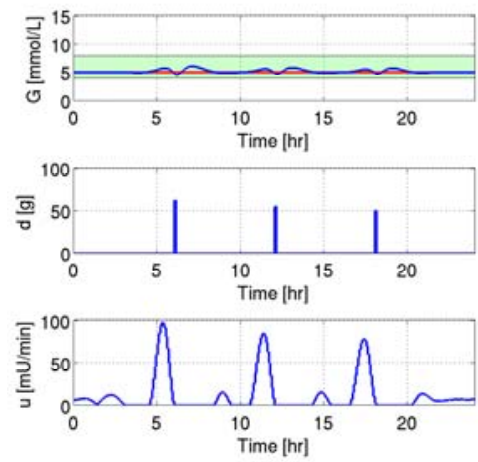

Fig. 2. Glucose profile (top), meal disturbances profile (middle) and insulin administration profile with meal announcement in advance.
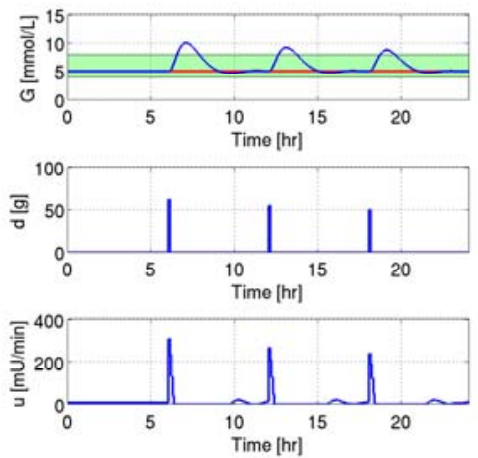

Fig. 3. Glucose profile (top), meal disturbances profile (middle) and insulin administration profile with meal announcement at mealtime.

shooting based algorithm described in Boiroux et al. (2009a) to solve the nonlinear program (1).

In the scenario considered, the simulated $70 \mathrm{~kg}$ subject has a $62 \mathrm{~g} \mathrm{CHO}$ meal at 6:00, a $55 \mathrm{~g} \mathrm{CHO}$ meal at 12:00, and a $50 \mathrm{~g} \mathrm{CHO}$ meal at 18:00. Fig. 2 illustrates an optimal insulin administration profile for the described scenario in the case where the controller knows the size and time of all meals in advance. Knowing the meal times and sizes allows the controller to deliver anticipatory insulin to avoid postprandial hyperglycaemia. However, the assumption that the patient would know in advance - and with accuracy - the meal times and sizes is not practical. Safety considerations would preclude significant amounts of insulin from being delivered prior to mealtime (as in this ideal scenario).

Fig. 3 shows the simulation results for the case in which the meals are announced to the MPC only at mealtime. Thus, the controller can deliver no anticipatory insulin prior to meals. The limitations for this case force the subject into (mild) hyperglycaemia, but hypoglycaemia is avoided. The insulin delivery profile for this case looks quite similar to bolus delivery of insulin by a pen; most of the meal-related insulin is delivered in bolus form in the few samples after the meals are taken (and announced).

\section{Bolus calculator and control}

In this section we describe an offset-free feedforward-feedback controller to compute optimal insulin profiles. Garcia-Gabin et al (2008) and Marchetti et al. (2008) established that a time-varying glucose setpoint can reduce the risk of hypoglycemia. The feedforward controller consists of a bolus calculator. It computes the optimal bolus size and the glucose setpoint, based on the meal size announced by the patient. The feedback controller adjusts the basal insulin infusion rate to compensate for mismatches in meal announcement and variations in the physiological parameters of the patient. The calculation of the basal insulin is based on a linear MPC algorithm.

We use the Hovorka model and the offset-free linear MPC algorithm developed in Boiroux et al. (2011) to compute the optimal insulin administration profiles for people with type 1 diabetes. In the scenario considered, the glucose sensor provides a signal perturbated by a normally distributed white noise. We consider two cases. In the first case, we decrease the insulin sensitivity by $50 \%$ under fasting conditions. In the second 

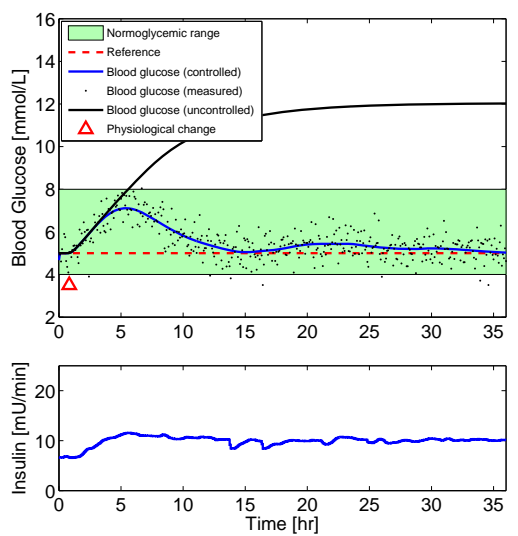

Fig. 4. and insulin administration (bottom) profile in the case wherethe insulin sensitivity decreases by $50 \%$ after 1 hour.
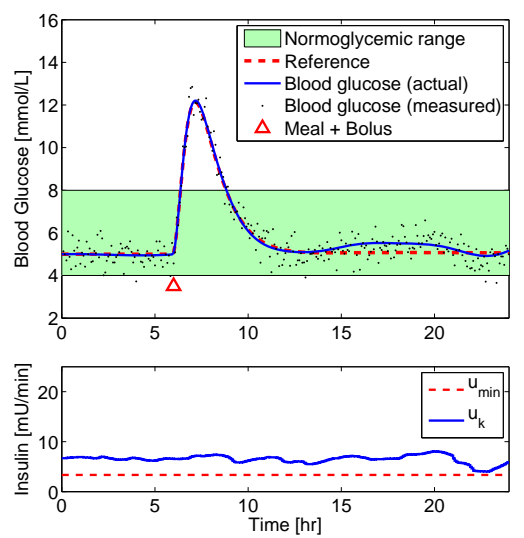

Fig. 5. Blood glucose (top) and insulin administration (bottom) profile in the case where the right meal size is announced

case, the patient has one $75 \mathrm{~g}$ CHO meal 6 hours after the beginning of the simulation. In the case where the patient has a meal, we consider the cases where the correct meal size is announced, the meal size is underestimated by $50 \%$ and the meal size is overestimated by $50 \%$.

Fig. 4 illustrates the blood glucose and the insulin profiles in the case where a change in the insulin sensitivity occurs while the patient is fasting, with sensor noise. The insulin infusion rate increases to reject the disturbance caused by the decrease in insulin sensitivity. In the uncontrolled case where the basal insulin infusion rate is not adjusted, the blood glucose tends to a new steady state in the hyperglycemic range.

For the case where the exact meal size is announced (Fig. 5), the insulin infusion rate remains close to the basal rate. Consequently, the blood glucose follows tightly the glucose setpoint. For the case where the meal size is underestimated (Fig. 6), the basal rate increases after the mealtime to compensate for the too low bolus. For the case where the meal size is overestimated (Fig. 7), the insulin infusion rate is at the minimum after the meal to compensate for the too high bolus. No hypoglycemic events occur when a meal is announced. However, the postprandial blood glucose excursion is bigger when the meal size is underestimated by the patient.

These results show that reasonably good control can be obtained when a feedforwardfeedback strategy is used, even for uncertain systems. However, the main limitation of this strategy is that a fairly good nonlinear model description of the patient must be available.

\section{Conclusion}

In this paper we applied nonlinear model predictive control to compute the optimal insulin profiles for people with type 1 diabetes. These profiles give an upper-bound on the maximal achievable performance in the cases where the meals are announced beforehand, and in the case where meals are announced at mealtimes only. We utilized the bolus-like nature of the optimal insulin profile to design an offset-free feedforwardfeedback controller. The feedforward part is a model-based bolus calculator, while the 

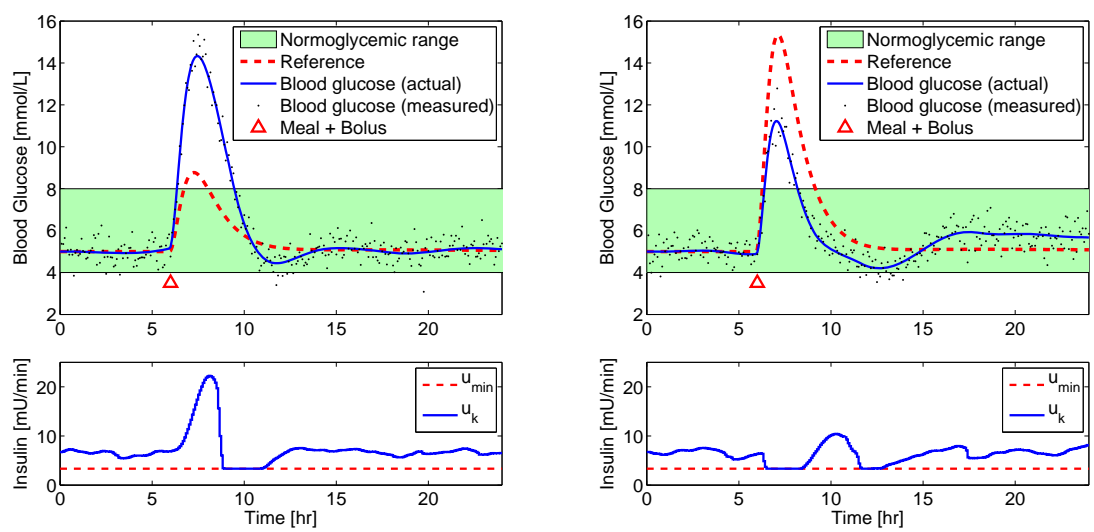

Fig. 6. Blood glucose profile(top) and insulin profile (bottom). Meal size underestimated by $50 \%$.

Fig. 7. Blood glucose profile(top) and insulin profile (bottom). Meal size overestimated by $50 \%$.

feedback part adjusts the basal insulin infusion rate. The numerical results demonstrate that a rather good control of blood glucose can be obtained, assuming that a fairly good physiological model of the patient can be identified.

\section{References}

Boiroux, D.; Finan, D.A.; Jørgensen, J.B.; Poulsen, N.K.; Madsen, H.: Implications and limitations of ideal insulin administration for people with type 1 diabetes, UKACC International Conference on Control 2010, pages 156-161, 2010a

Boiroux, D.; Finan, D.; Jørgensen, J.; Poulsen, N.; Madsen, H.: Optimal insulin administration for People with Type 1 Diabetes, proceedings of the $9^{\text {th }}$ International Symposium on Dynamics and Control of Process Systems (DYCOPS 2010), pages 234-239, 2010b

Boiroux, D.; Finan, D.; Jørgensen, J.B.; Poulsen, N.K.; Madsen, H.: Strategies for glucose control in people with type 1 diabetes, IFAC world congress 2011. Submitted

Cobelli, C.; Dalla-Man, C.; Sparacino, G.; Magni, L.; De Nicolao, G.; Kovatchev, B.P.: Diabetes: models, signals, and control, IEEE Reviews in Biomedical Engineering, 2, 2009, 54-96

Garcia-Gabin, W.; Vehi, J.; Bondia, J.; Tarin, C.; Calm, R.: Robust sliding mode closed-loop glucose control with meal compensation in type 1 diabetes mellitus, proceedings of the $18^{\text {th }}$ world congress, the international federation of automatic control, pages 4240-4245, 2008

Hovorka, R.; Canonico, V.; Chassin, L.J.; Haueter, U.; Massi-Benedetti, M.; Frederici, M.O.; Pieber, T.R.; Schaller, H.C.; Schaupp, L.; Vering, T.; Wilinska, E.: Nonlinear model predictive control of glucose concentration in subjects with type 1 diabetes, Physiological measurements, 25, 2004, 905-920

Klonoff, D.C.; Cobelli, C.; Kovatchev, B.; Zisser, H.C.: Progress in development of an artificial pancreas, Journal of Diabetes Science and Technology, 3, 2009, 1002-1004

Marchetti, G.; Barolo, M.; Jovanovič, L.; Zisser, H.; Seborg, D.E.: A feedforward-feedback glucose control strategy for type 1 diabetes mellitus, Journal of process control, 2008, 18(2), $149-162$ 